\title{
Vegetative cover and PAHs accumulation in soils of urban green space
}

\author{
Chi Peng, Zhiyun Ouyang, Meie Wang, Weiping Chen*, Wentao Jiao \\ State Key Laboratory of Urban and Regional Ecology, Research Center for Eco-environmental Sciences, Chinese Academy of Sciences, Beijing 100085, PR China
}

\section{A R T I C L E I N F O}

\section{Article history:}

Received 4 July 2011

Received in revised form

19 September 2011

Accepted 27 September 2011

\section{Keywords:}

Polycyclic aromatic hydrocarbons

Urban soil

Land use

Vegetation

Soil organic matter

Beijing

\begin{abstract}
A B S T R A C T
We investigated how urban land uses influence soil accumulation of polycyclic aromatic hydrocarbons (PAHs) in the urban green spaces composed of different vegetative cover. How did soil properties, urbanization history, and population density affect the outcomes were also considered. Soils examined were obtained at 97 green spaces inside the Beijing metropolis. PAH contents of the soils were influenced most significantly by their proximity to point source of industries such as the coal combustion installations. Beyond the influence circle of industrial emissions, land use classifications had no significant effect on the extent of PAH accumulation in soils. Instead, the nature of vegetative covers affected PAH contents of the soils. Tree-shrub-herb and woodland settings trapped more airborne PAH and soils under these vegetative patterns accumulated more PAHs than those of the grassland. Urbanization history, population density and soil properties had no apparent impact on PAHs accumulations in soils of urban green space.
\end{abstract}

Crown Copyright $\odot 2011$ Published by Elsevier Ltd. All rights reserved.

\section{Introduction}

Green spaces are vital elements of modern cities. They enhance the quality of urban residents' life by refreshing them from mental fatigue, reducing their stress levels, and providing them open space for physical and recreational activities (Grahn and Stigsdotter, 2010; Schipperijn et al., 2010). About 70\% dwellers of Beijing utilize the open green spaces at least once a week (Lo and Jim, 2010). Besides the aesthetic enhancements, urban green spaces also have ecological and environmental benefits. They produce food, harbor biodiversity, alter urban microclimate, generate oxygen, break up strong winds, reduce noise, and improve air quality (Escobedo and Nowak, 2009; Kong et al., 2010; Rafiee et al., 2009; Shan et al., 2007; Yang et al., 2005). Meanwhile, urban areas are geographical regions of intense resource inputs, energy consumptions and waste emissions. In urban settings, harmful contaminants may be inadvertently released into the atmosphere and then deposited in the soil that has a large capacity for retaining persistent organic pollutants such as polycyclic aromatic hydrocarbons (PAHs) (Cai et al., 2007; Wong et al., 2004).

PAHs are ubiquitous environment contaminants produced by incomplete combustion of organic substances (Agarwal, 2009; Aichner et al., 2007; Mantis et al., 2005) and some are human carcinogens prevalent in the modern cities (Szabová et al., 2008).

\footnotetext{
* Corresponding author.

E-mail addresses: chenweip@yahoo.com.cn, wpchen@rcees.ac.cn (W. Chen).
}

PAHs accumulated in urban soils may have a direct impact on public health as they are readily transferable into human body via ingestion, inhalation, and dermal contact (Jiang et al., 2009). Furthermore, they may exhibit toxic effects toward plants and soil biota (Andreoni et al., 2004). The United States Environmental Protection Agency (USEPA) identified 16 priority PAHs as targets of regulatory attention that have become focuses of environmental investigations worldwide (Hao et al., 2007; Nam et al., 2008; Wang et al., 2007; Wong et al., 2004).

Once released, the distribution and fate of PAHs in the environment are affected by factors including ambient temperature, intensity and direction of prevailing wind, precipitation pattern, vegetation, and physicochemical properties and microbial activities of soils (Diamond and Hodge, 2007; Heywood et al., 2006). PAH concentrations are substantially lower in the less populated rural than the densely populated urban areas (Jensen et al., 2007). Soils of higher PAH concentrations are found in the proximity of emission sources that are susceptible to high rates of airborne depositions (Nam et al., 2008). Therefore, the urban land uses that determine locations of emission sources, patterns of transport and deposition, and characteristics of receptors are crucial factors influencing PAHs accumulation in the soils. Moreover, PAHs are adsorbed by soil organic matter (SOM) and volatilization, degradation and leaching of adsorbed PAHs are inhibited (Yu et al., 2006). The chemical properties of PAH congeners would eventually determine the extent of its fate in the soils (Nam et al., 2008; Wang et al., 2007; Zhang et al., 2006a). In all, 90\% of the PAHs in the terrestrial environment accumulate in the soils (He et al., 2009). 
Forests are effective of scavenging airborne lipophilic organic compounds and depositing them in the soils (Staci and Simonich, 1994). Trees remove gaseous air pollution via leaf stomata uptake and absorption at the cuticles (Wania and McLachlan, 2001). Meanwhile the foliar canopy will intercept airborne particulate pollutants (Nowak et al., 2006). The intercepted PAHs are directly deposited on the ground, washed off the trees by rains, and dropped along with falling leaves and twigs. The stagnant atmosphere underneath the tree canopy likely will slow down the volatilization of PAHs from soils (Cousins et al., 1999). Furthermore, once volatilized from the soil in which the vegetation is growing, PAHs may subsequently be reabsorbed by plants and start the cycling over (Collins and Finnegan, 2010). Urban tree stands may therefore play a significant role in deciding the environmental fate of PAHs, decreasing their airborne half-life and transferring the chemical from the atmosphere to the soils (McLachlan and Horstmann, 1998). The deposition fluxes of PAHs are much greater in forests than adjacent grasslands (Hassanin et al., 2003; Meijer et al., 2002).

The vegetated open spaces in urban settings were expected to modulate PAH accumulations in surface soils (Tam and Wong, 2008). Plants might take up soil borne PAHs thus reducing their contents of the soils (Gao and Zhu, 2004; Lin et al., 2007; Watts et al., 2006). More importantly, plants might attenuate the PAH contaminated soils by providing a conducive environment for growth and metabolism of soil microorganisms through releases of nutrients and enzymes and transport of oxygen to the rhizosphere (Macek et al., 2000). Although PAH could undergo photochemical degradation and chemical oxidation, microbial degradation was by far the most significant process of PAH elimination in the soil (Haritash and Kaushik, 2009).

We hypothesized that the deposition and accumulation of PAHs in soils are affected interactively by the way urban land was used, nature of vegetative covers constituted the open spaces, and characteristics of soil in reacting with PAHs. This study identified the PAHs accumulation in the primary land use categories of urban environment, described how the vegetation patterns influencing PAH contents of soils, and delineated effects of soil properties, urbanization history and population density on PAHs accumulation in urban green spaces of Beijing.

\section{Material and methods}

\subsection{Study area}

Beijing is the largest yet typical metropolis of northern China with rapid urban development, dense population, heavy pedestrian and automobile traffic, rapid industrialization, and in the winter large-scale coal-fired heating installations throughout the City. The $650 \mathrm{~km}^{2}$ city proper is anchored by the Forbidden City at the center and surrounded by five concentric squares of developments and circular traffic throughways (i.e. the ring roads). The city is interspersed with green and open spaces characterized by woods, parks, greenbelts, school grounds, roadside trees, and grassy open fields covering $44.4 \%$ of the surface areas. The population has exceeded 16 million and growing. The intense human activities and supporting services bringing in food, water, and energy may strongly influence the ecological integrity of the metropolitan area. The PAHs are found in Beijing's air and soils (Jiao et al., 2009; Li et al., 2006; Ma et al., 2005; Tang et al., 2005; Yu et al., 2008). The emissions from automobile traffic, coal combustion for domestic heating, and industrial activities are primary sources of PAHs in Beijing (Peng et al., 2011).

\subsection{Sampling description}

Ninety seven sites where the soil profile had not been recently disturbed were selected for soil sampling. They spread out across the City (Fig. 1) representing the green/open spaces of different vegetation compositions and were located in neighborhoods of different land uses (Table S1). Each collected sample was the composite of five $0-10 \mathrm{~cm}$ depth soil cores obtained within a $10 \mathrm{~m} \times 10 \mathrm{~m}$ area using a stainless steel hand auger. The sampling areas were at least $10 \mathrm{~m}$ away from the edge of the prescribed green space. After removing the vegetative debris, samples were air-dried at room temperature and then ground to pass a sieve of $2 \mathrm{~mm}$ openings. The finished soil samples were stored in amber color glass container at $-25^{\circ} \mathrm{C}$ until time for chemical analyses.

The sampling locations were divided according to eight land use categories namely industries, school grounds, residential communities, roadsides of heavy traffic and light traffic, plantations, and vacant lots and four vegetative cover classes namely greenbelt, tree-shrub-herb composite, woodland, and grassland. The selections were intended to cover all potential PAH emission and receptor sources and all vegetation compositions that might influence its distribution and accumulation in soils of Beijing proper. The locations were categorized as follows. Greenbelts, 15 locations, represented narrow green space along major thoroughfares and promenades that were well landscaped and routinely maintained. Tree-shrubherb settings, 37 locations, were urban ornamental garden with multilayer composition consisting of trees, shrubs and herbaceous plants that organize as a parterre in residential communities, public parks, and other institutions accessible to the public. Woodlands, 27 locations, consisted of tree stands with little shrub and grass understory. Grasslands, 18 locations, were open space with ornamental lawn or nature grass covers. Industrial facilities, 7 locations, consisted of soils underneath varieties of vegetative covers at 5 just-closed large industrial complexes and two

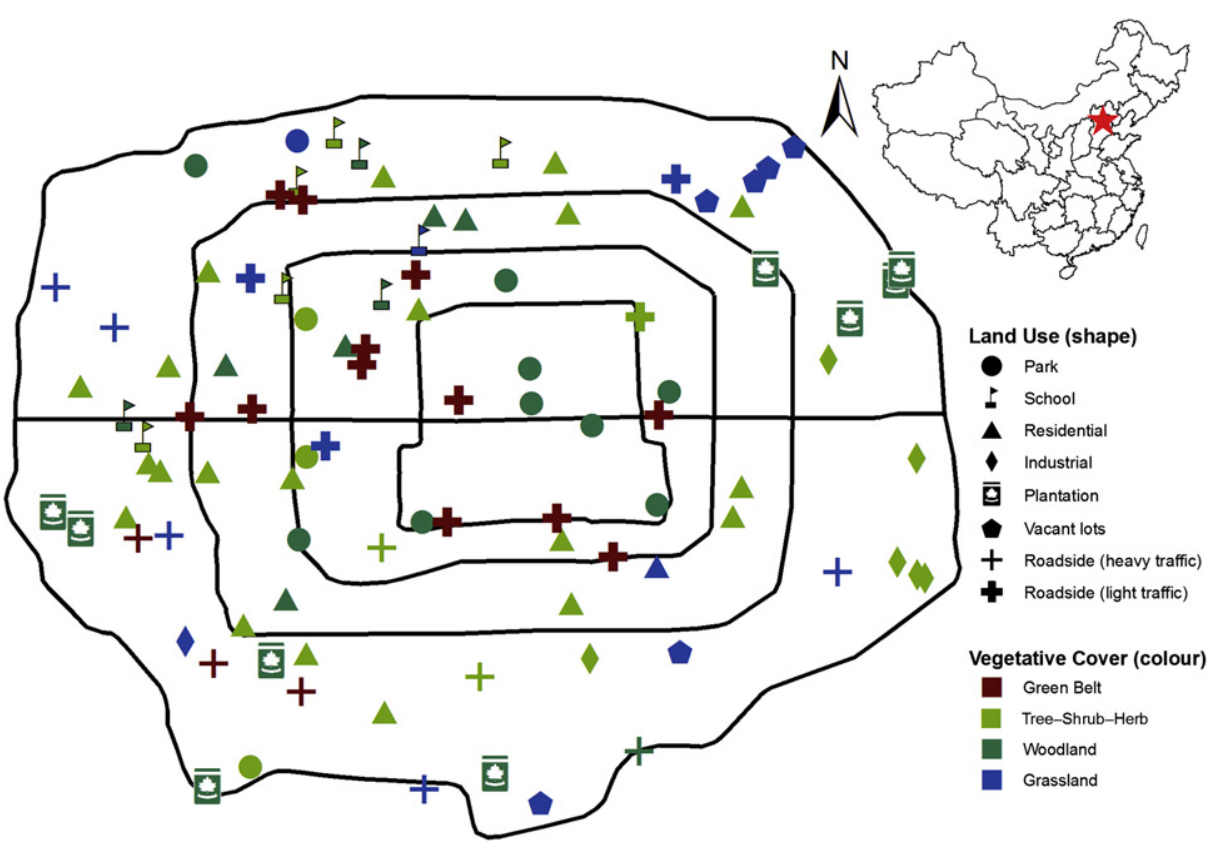

Fig. 1. Location of sample collection sites by land use and vegetative cover. 
municipal wastewater treatment plants. Roadsides were sections of roads lined with closely cropped trees and were further divided according to designation of the municipality into roads of heavy traffic, 16 locations and roads of light traffic, 11 locations. Other land use categories such as park, 13 locations; vacant lot, 6 locations; residential settings, 26 locations; plantation, 9 locations, and school, 9 locations were selected for their omnipresence throughout the cities.

\subsection{PAH analysis}

The soil samples in $5 \mathrm{~g}$ aliquot along with $5 \mathrm{~g}$ anhydrous sodium sulfate were extracted in an Automated Soxhlet apparatus (BUCHI B-811, Inc., Switzerland) with

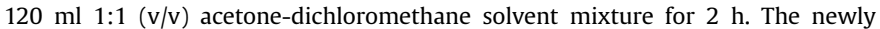
developed apparatus allowed soil samples be extracted in continuous solvent flow under warm or hot temperature therefore significantly reduced the time for extraction. The extracts was concentrated under a gentle nitrogen stream and then purified by passing through a solid-phase silica-gel extraction column (Supelco Inc., USA). The PAHs in the purified extract were analyzed by an Agilent 6890 gas chromatography equipped with a 5975C mass selective detector (GC-MSD). Oven temperature was programmed as follows: $50{ }^{\circ} \mathrm{C}$ held for $1 \mathrm{~min}$, increased to $150{ }^{\circ} \mathrm{C}$ at $25^{\circ} \mathrm{C} / \mathrm{min}$ held for $1 \mathrm{~min}$ and then increased to $300^{\circ} \mathrm{C}$ at $4{ }^{\circ} \mathrm{C} / \mathrm{min}$ held for $4.5 \mathrm{~min}$. The mass scan mode was selective ion monitoring (SIM).

The external standard method was used to determine the following 16 EPA priority PAHs: Naphthalene (NAP), Acenaphthylene (ACPY), Acenaphthene (ACP), Fluorene (FL), Phenanthrene (PHE), Anthracene (ANT), Fluoranthene (FLT), Pyrene (PYR), Chrysene (CHR), Benzo(a)anthracene (BaA), Benzo(k)fluoranthene (BkF), Benzo(b)fluorantene (BbF), Benzo(a)pyrene (BaP), Dibenzo(a, h)Anthracene(DBA), Indeno(1, 2, 3-cd)pyrene (IND), and Benzo(g, h, i)perylene (BghiP). The standard solutions of PAHs were obtained from Supelco Inc., USA. The total $16 \mathrm{PAH}$ concentrations in method blanks were less than $20 \mathrm{ng} / \mathrm{g}$. The PAH recovery ratios of matrixspiked samples were $64 \%$ for NAP, and $86 \%-119 \%$ for the remaining PAHs. Replicated analyses showed a replicated percentage deviation between $-20 \%$ and $+20 \%$ for PAHs in soils.

\subsection{SOM and $\mathrm{pH}$ analysis}

Total organic carbon contents of soils were determined by combustion method using an elemental analyzer (Elementar, Germany). Prior to the analysis, carbonates were eliminated by treating the soil with $10 \% \mathrm{HCl}$ and then air drying the vacuum filter recovered soil overnight. The soil organic matter (SOM) was obtained by multiplying measured organic carbon content of the soil by 1.724 (Nascimento et al., 2004). Soil pH was determined in distilled water at a soil-to-solution ratio of 1: 2.5 .

\subsection{Data analysis}

The statistical inferences of data were determined using the analyses of variance (ANOVA) with least significant difference test, Kolmogorov-Smirnov goodness of fit test, regression analysis, and Pearson correlation analysis software packages in the SPSS (version 18.0). When applicable, the data were log-transformed into the normal distribution for statistical analyses.

\section{Results and discussions}

\subsection{Effects of land use types on PAHs accumulation}

PAHs are ubiquitous in the Beijing metropolitan area. All 16 PAHs were detected in every soil sample we collected. Based on the total mass concentration of USEAP 16 priority PAH ( $\Sigma$ PAHs), the soils in the vicinity of industrial establishments accumulated the highest amounts of PAHs at mean of $4768 \mathrm{ng} / \mathrm{g}$ with a standard deviation of $5548 \mathrm{ng} / \mathrm{g}$, reflecting the significance of point source emissions and wide dispersion of PAH emissions of the sources. The relative proportion of PAH congeners in the soil followed essentially the same pattern regardless of the land use categories (Table 1). Judging the means and respective standard of deviations, the data representing each land use category exhibited considerable degree of dispersion reflecting the variability of PAH concentrations within a category. The variability was caused by the differences in time periods, vegetative covers, soil organic matter and soil microbial activities.

The PAH concentrations of soils near Gaobeidian and Weijia Water Purification Plants, two major industrial complexes, recorded $\Sigma$ PAHs $=406$ and $378 \mathrm{ng} / \mathrm{g}$, respectively that were the lowest among the industrial land use category. Apparently, no substantive combustion installation was on sites. Had these two locations been excluded, the mean $\Sigma$ PAHs of the industrial areas would be 3 times higher than that of school grounds (the next highest category), and more than 5-12 times higher than that in park, roadsides of heavy traffic, residential area, plantation, wasteland, roadsides of light traffic and vacant lots $(p<0.05)$. The soils at two industrial locations associating with coal combustions recorded the highest ¿PAHs concentrations in Beijing, $13141 \mathrm{ng} / \mathrm{g}$ for Beijing Coking Plant and 11650 ng/g for Beijing Carbonization Plant. The coal combustion processes though relocated left lasting legacies inside the city and contributed heavily to the accumulation of PAHs in soils of the surrounding green spaces. For future development of land parcels, the PAH tainted soils would have to be remediated.

The automobile exhausts were also significant sources of PAHs in Beijing (Li et al., 2006; Tang et al., 2005). Consequently, the PAH concentrations of soils at roadsides of heavy traffic were significant higher than those at roadsides of light traffic $(p<0.05)$. The automobile exhausts were emitted close to the ground and the road

Table 1

Mean and standard deviation of PAH concentrations in urban soils of Beijing.

\begin{tabular}{|c|c|c|c|c|c|c|c|c|}
\hline & \multicolumn{8}{|c|}{ PAH concentration of soil according to land use (ng/g, mean \pm S.D.) } \\
\hline & Industrial & School & Park & $\begin{array}{l}\text { Roadside } \\
\text { (heavy traffic) }\end{array}$ & Residential & Plantation & $\begin{array}{l}\text { Roadside } \\
\text { (light traffic) }\end{array}$ & Vacant lots \\
\hline NAP & $54 \pm 48$ & $20 \pm 11$ & $28 \pm 43$ & $24 \pm 17$ & $21 \pm 12$ & $14 \pm 8$ & $10 \pm 7$ & $8 \pm 2$ \\
\hline ACPY & $51 \pm 69$ & $17 \pm 17$ & $15 \pm 25$ & $12 \pm 7$ & $9 \pm 8$ & $7 \pm 5$ & $8 \pm 6$ & $5 \pm 3$ \\
\hline ACP & $48 \pm 65$ & $7 \pm 8$ & $6 \pm 8$ & $4 \pm 3$ & $3 \pm 4$ & $3 \pm 1$ & $2 \pm 1$ & $2 \pm 1$ \\
\hline $\mathrm{FL}$ & $52 \pm 63$ & $16 \pm 12$ & $12 \pm 9$ & $12 \pm 7$ & $12 \pm 12$ & $8 \pm 2$ & $8 \pm 3$ & $8 \pm 3$ \\
\hline PHE & $404 \pm 447$ & $156 \pm 154$ & $110 \pm 128$ & $93 \pm 65$ & $91 \pm 101$ & $61 \pm 23$ & $50 \pm 29$ & $54 \pm 33$ \\
\hline ANT & $142 \pm 199$ & $31 \pm 37$ & $23 \pm 36$ & $19 \pm 18$ & $14 \pm 13$ & $10 \pm 5$ & $11 \pm 7$ & $11 \pm 9$ \\
\hline FLT & $634 \pm 758$ & $260 \pm 307$ & $167 \pm 232$ & $124 \pm 112$ & $105 \pm 108$ & $85 \pm 53$ & $64 \pm 42$ & $71 \pm 45$ \\
\hline PYR & $515 \pm 625$ & $204 \pm 238$ & $132 \pm 185$ & $99 \pm 85$ & $80 \pm 78$ & $66 \pm 43$ & $51 \pm 35$ & $56 \pm 35$ \\
\hline $\mathrm{BaA}$ & $349 \pm 411$ & $138 \pm 164$ & $85 \pm 135$ & $65 \pm 53$ & $51 \pm 49$ & $42 \pm 31$ & $35 \pm 26$ & $35 \pm 20$ \\
\hline CHR & $443 \pm 511$ & $174 \pm 185$ & $116 \pm 160$ & $91 \pm 62$ & $74 \pm 62$ & $64 \pm 41$ & $49 \pm 30$ & $45 \pm 20$ \\
\hline $\mathrm{BbF}$ & $461 \pm 516$ & $212 \pm 229$ & $133 \pm 191$ & $107 \pm 72$ & $83 \pm 70$ & $74 \pm 55$ & $57 \pm 36$ & $51 \pm 20$ \\
\hline $\mathrm{BkF}$ & $452 \pm 508$ & $195 \pm 215$ & $127 \pm 187$ & $100 \pm 69$ & $77 \pm 64$ & $72 \pm 53$ & $54 \pm 34$ & $49 \pm 19$ \\
\hline $\mathrm{BaP}$ & $376 \pm 447$ & $173 \pm 207$ & $100 \pm 154$ & $80 \pm 67$ & $58 \pm 58$ & $49 \pm 40$ & $40 \pm 28$ & $39 \pm 20$ \\
\hline IND & $341 \pm 395$ & $177 \pm 214$ & $102 \pm 157$ & $85 \pm 59$ & $58 \pm 54$ & $50 \pm 38$ & $41 \pm 27$ & $38 \pm 17$ \\
\hline DBA & $92 \pm 110$ & $37 \pm 46$ & $23 \pm 40$ & $17 \pm 13$ & $12 \pm 10$ & $11 \pm 9$ & $9 \pm 6$ & $8 \pm 3$ \\
\hline BghiP & $347 \pm 405$ & $164 \pm 199$ & $100 \pm 160$ & $85 \pm 57$ & $56 \pm 50$ & $50 \pm 37$ & $41 \pm 28$ & $37 \pm 15$ \\
\hline LMW PAHs & $753 \pm 878$ & $250 \pm 227$ & $196 \pm 247$ & $166 \pm 102$ & $153 \pm 146$ & $105 \pm 43$ & $91 \pm 51$ & $90 \pm 51$ \\
\hline HMW PAHs & $4014 \pm 4678$ & $1738 \pm 1996$ & $1089 \pm 1603$ & $860 \pm 634$ & $657 \pm 605$ & $568 \pm 401$ & $446 \pm 293$ & $432 \pm 214$ \\
\hline$\sum \mathrm{PAHs}$ & $4768 \pm 5548$ & $1989 \pm 2217$ & $1285 \pm 1848$ & $1026 \pm 726$ & $811 \pm 748$ & $673 \pm 442$ & $538 \pm 340$ & $523 \pm 259$ \\
\hline
\end{tabular}


lined with greenbelt formed a barrier that prevented much of the fugitive pollutants such as PAHs from spreading. The mobile source PAHs emitted by moving motor vehicles nevertheless was diffused and tended to be deposited along direction of the traffic. Meanwhile, the stationary source PAHs emissions of the industrial establishments were more concentrated and tended to be deposited near the vicinity of emission sources following the direction of prevailing wind. The patterns were reflected in the distinctively different soil PAH concentrations of these two land use categories. The soils at school grounds also exhibited high PAH concentrations that might be due to the long history of burning coal for onsite space heating during winter months. The plantations and vacant lots were found in the less populated and more remote outskirt locations that were outside of the 4th ring road far away from point emission sources and heavily traveled roads thus exhibited the lowest soil PAH concentrations. However, the outcomes of ANOVA test showed that PAH concentrations of soils in Beijing were not significantly different between the land use categories if the industrial land use category was excluded. It appeared that the variance caused by the point source emissions at industrial complexes was more significant than the variances associated with other factors of land use classifications such as mobile source, population density and the distance to urban center.

$\mathrm{PAH}$ emitted from different emission sources would have different congener compositions. In a large metropolis such as Beijing, PAH emission sources were numerous and diverse. There were point sources and diffused non-point sources and there were stationary sources and mobile sources. They scattered throughout the city. Hypothetically, the compositions of PAH congeners in receiving soils would change according to $\mathrm{PAH}$ emitted from sources of land use categories. However, the relative contributions of PAH congeners toward the $\sum$ PAHs of the eight land use categories were essential the same (Fig. S1) when the congener distributions were tested according to Kolmogorov-Smirnov goodness of fit. The outcomes of Pearson correlation matrix (Table 2) showed that the concentrations of PAH congeners in soils were significant correlated $(p<0.01)$ indicating PAH deposited in soils of different land use categories encountered comparable environmental fate and transport processes. The low molecular weight PAHs were more volatile and had considerably higher Henry's Law constant and shorter degradation half-life. Once emitted, they would less likely be adsorbed by airborne particulates. The molecules in gaseous forms would be susceptible to rapid photolysis. The high molecular weight PAHs were associated with airborne particulates and were prone to deposition according to particle sizes. Consequently, the larger PAH containing particles deposited and accumulated in soils close to the emission source (Nam et al., 2008; Wang et al., 2007) and smaller PAH containing particles would be airborne and suspended for longer period of time. The fact that the relative compositions of PAH congeners of soils were comparable across the land use categories appeared to indicate that this class of suspended PAH containing particulates from different sources were intermingle throughout the air-shed. In this manner, the PAH profiles influenced by the industrial emissions were compensated by the emissions from other sources such as home heating and domestic cooking. The PAH compositions of soils in Beijing were thus equalized through degradation of low molecular weights PAHs upon emission coupled with the mixing and transport of PAH containing particulates prior to the deposition.

\subsection{Effects of vegetative covers}

The USEPA 16 priority PAHs concentrations of soils under the vegetative covers of tree-shrub-herb, greenbelt, woodland, and grassland were $1782,1117,1101$, and $455 \mathrm{ng} / \mathrm{g}$, respectively (Fig. 2).

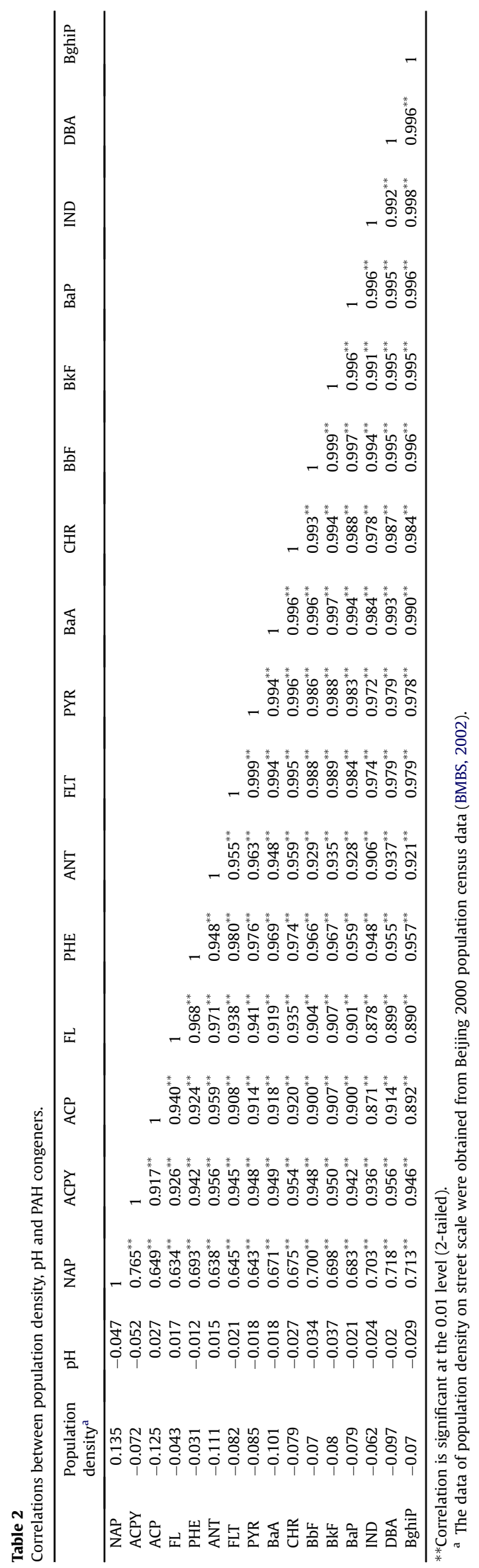




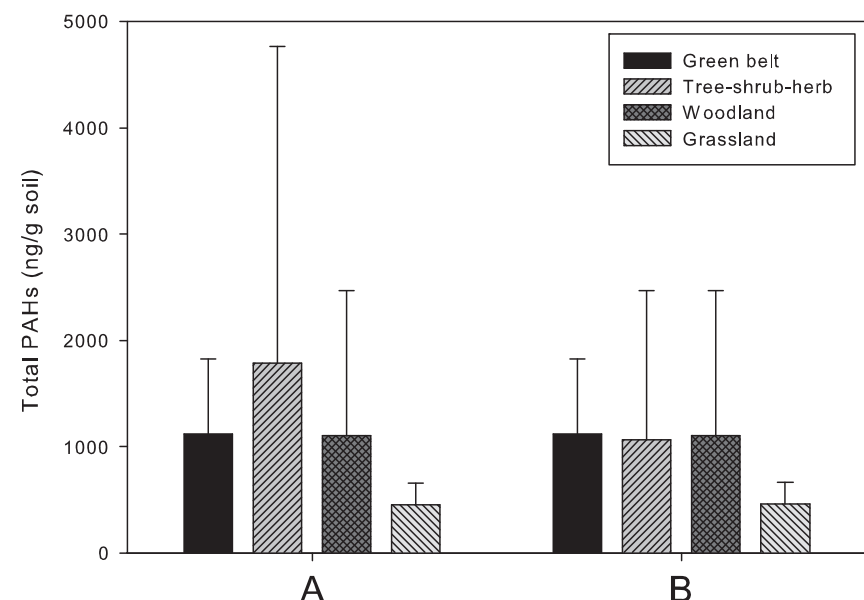

Fig. 2. Mean and standard deviation of $P A H$ concentrations in soils having different vegetative covers, A: All relevant data (97 observations); B: Excluding data representing industrial areas (90 observations).

The PAHs accumulations of the tree-shrub-herb and woodland settings were respectively 3 and 2 times higher than that in grassland $(p<0.05)$. When the green space was in the proximity of a strong emission source such as an industrial complex, effects of vegetative covers were shadowed by the heavy depositions. Meanwhile, the land uses in terms of PAH accumulation in the soils could be divided into two categories based on results of ANOVA, namely industrial area and other land uses. When the data representing locations subjected to direct influences of industrial emissions were excluded, the soil PAH concentrations of the treeshrub-herb, roadside, and woodland vegetative classes became comparable (Fig. 2B) and were two times higher than that of the grassland $(p<0.05)$. The grassland type of open space in urban area on the other hand has a low vertical profile to capture PAHs suspended in the air stream and would rely entirely on direct deposition for PAHs to accumulate in the soils. Besides, a significant part of the grassland is lawns that are mowed and whose clippings are removed regularly. They were the urban green spaces least impacted by the PAHs.

The forests were more efficient than grassland or non-vegetated in capturing PAH particulates suspended in the atmosphere. Larger canopy and diversified species composition would enhance interception of airborne pollutants (Jim and Chen, 2008; Yang et al., 2005). For example, the tree-shrub-herb and woodland settings had multiple layers of vegetation including understory and groundcover plants that were effective in trapping airborne PAHs. Consequently, soil PAHs accumulations in tree-shrub-herb and woodland settings were not significantly different.

The urban vegetation captured the airborne pollutants and helped to improve the urban air quality (Jim and Chen, 2008; Nowak et al., 2006) yet soils of the urban green spaces would accumulate PAHs. The high PAH concentrations in urban soils might inevitably expose residents to potential carcinogens and subject soil ecosystems to potentially harmful substances.

\subsection{Effects of urbanization history and population density}

Urbanization history, length of time the location had been urbanized, and population density would influence might influence the pollutants concentrations of urban soils (Chen et al., 2005; Liu et al., 2008; Xia et al., 2011). Beijing in the past several decades had expanded from the ancient inner city outward through sustained urban renewal and development. We divided urban Beijing into four parts according to the progression of urban development as represented by the concentric ring roads and organized the data accordingly. The PAH concentration of soils in these four progressively newer urban sectors bordered by the ring roads were not significant different, $p>0.05$ (Fig. 3). It appeared that soil PAH contents of the inner city were primarily due to legacies of long human inhabitation yet soil PAH contents of the new development were influenced by a new sets of emission sources such as automobile traffics and industrial production activities. In concentric form, the surface areas of outer city are considerably larger than those of the inner city. As a result, the new developments in Beijing accumulated far greater amounts of PAH in the soils.

Earlier reports had noted that PAH concentrations of urban soils differed according to population density of the cities (Hafner et al., 2005; Liu et al., 2008; Wang et al., 2011b; Zhang et al., 2006b). The population density in these cases denoted in essence characteristics of between cities and did not account for distribution of populations within the city. When the samples we collected were cataloged according to the population density of their respective sampling locations, it distinguished the population density within a city and showed that it did not significantly affect the PAH concentration of the soils (Table 2). Clearly, residential communities were not significant contributors of PAH emissions in Beijing. Natural gas has replaced coal as the primary fuel for domestic energy needs (Wang et al., 2011a; Xu et al., 2005). The improvements in combustion efficiency significant reduced amounts of PAH emitted from the domestic sources (Ravindra et al., 2008). The intensity and duration of PAH emissions due to community wide home heating installations were lower than that of the industrial combustion installations. Space heating needs were seasonal and heat generating facilities spread throughout the city. As emissions, their behavior mimicked those of non-point sources and acted merely to enhance the background levels.

\subsection{Effects of soil properties}

The organic matter contents of the soils in Beijing varied from $0.42 \%$ to $5.96 \%$ with a mean of $2.36 \%$. The linear regression between amounts of PAHs accumulated in and the organic matter contents of soils was significant at $p<0.01$ (Fig. 4A). According to the determination coefficient of regression equation, however, the soil organic matter accounted for less than $10 \%$ of the observed variations in soil PAHs. Eleven data points were above the horizontal line of $\Sigma$ PAHs $=2000 \mu \mathrm{g} / \mathrm{kg}$ and deviated from the remainder data

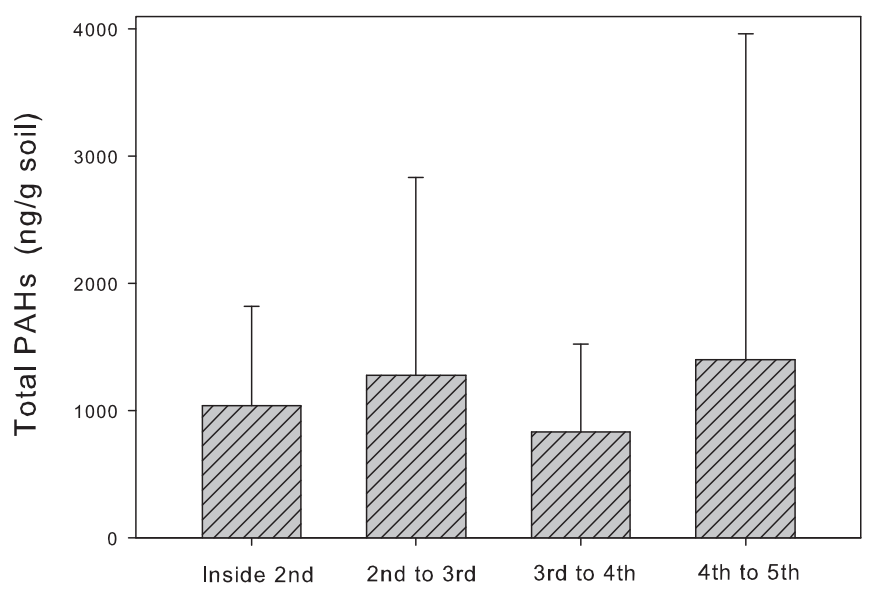

Fig. 3. Mean and standard deviation of PAH concentrations in the areas separated by the concentric ring roads of Beijing. 

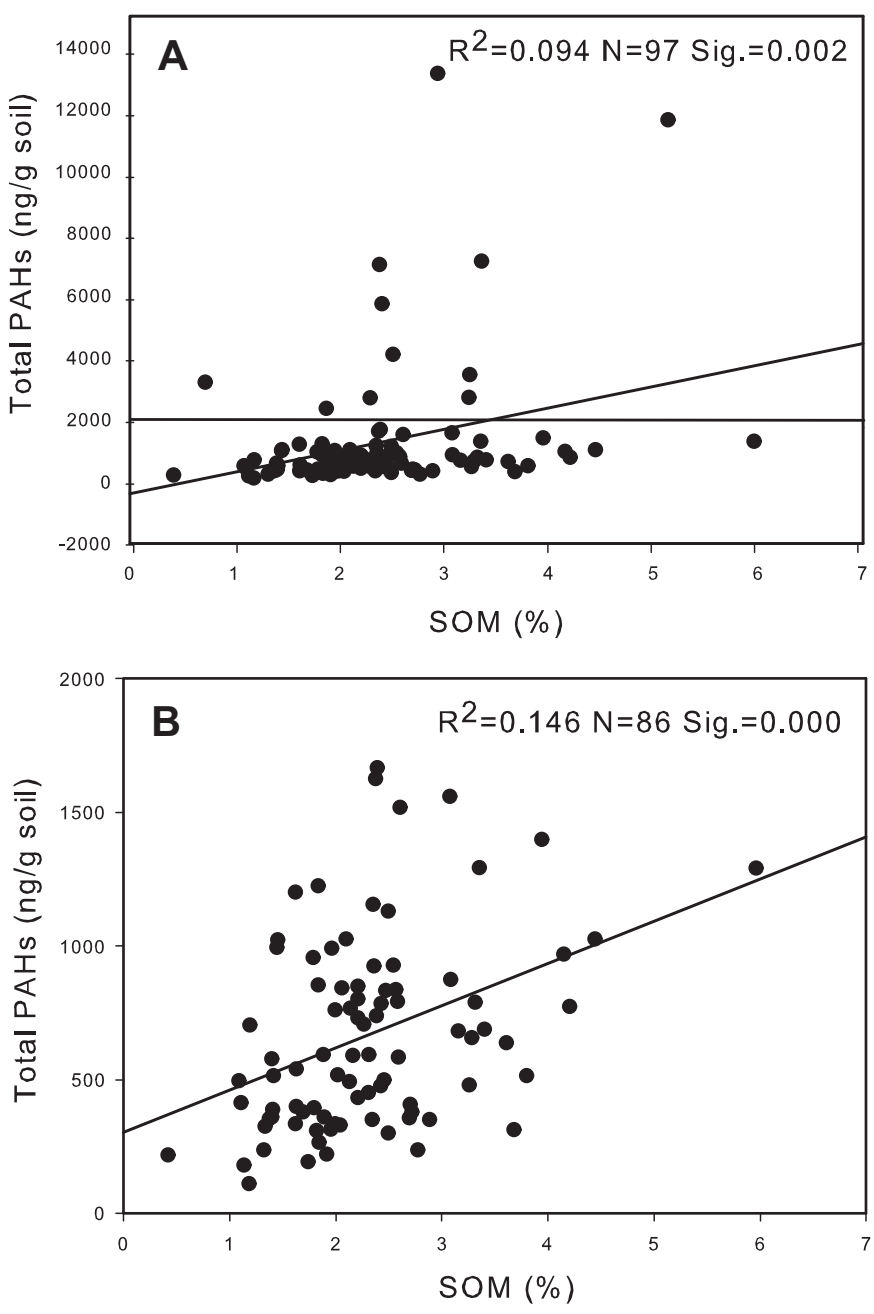

Fig. 4. Linear regression of SOM and total PAH content of soils (A) with all sampling data (97 observations), (B) with outliers of total $\mathrm{PAH}>2000 \mathrm{ng} / \mathrm{g}$ excluded (86 observations).

points that were much closely cropped (Fig. 4A). Their concentrations apparently influenced by factors other than the adsorptive characteristics of SOM. The outliers including three industrial sites, one roadside (heavy traffic), two parks, and wooded areas at one residential and four school sites. Fig. 4B showed the linear regression between PAHs and SOM of the soils when the outliers were excluded. The determination coefficient increased slightly from $9.4 \%$ to $14.6 \%$. The soil organic matter content though significantly related to soil PAHs was not the primary factor in determining $\mathrm{PAH}$ accumulation in urban soils.

The $\mathrm{pH}$ value of the soil ranged from 7.19 to 8.31, with a mean of 7.88. The Pearson correlation analysis showed there were no significant correlation between the soil PH and the PAH concentrations in soils (Table 2). Being non-polar organic compounds, the PAHs' mobility and accumulation in soils were not affected by the soil $\mathrm{pH}$ that ranged from 7.19 to 8.31 .

\section{Conclusions}

In all, emissions of fuel combustions in industrial complexes were by far the most significant factor in determining PAH accumulation in the soils of urban green spaces in metropolitan Beijing. Once outside of the area of immediately influenced by industrial emissions, the land use categories, nature of emission sources, population density, and length of time it had been urbanized had little effect of amount of PAHs in soils. Instead the vegetative cover was a significant factor. The tree-shrub-herb and woodland settings captured and accumulated more fugitive PAHs than that of the grassland setting in which the lawns were mowed and clippings were collected and removed regularly. The soil organic matter content though significantly related to soil PAHs was not the deciding factor on PAH accumulation in urban soils.

\section{Acknowledgments}

We gratefully acknowledged financial supports provided by the National Natural Science Foundation of China (Grant No. 41030744), the Technical Supporting Programs of China (Grant No. 2007BAC28B01) and the Special Foundation of State Key Lab of Urban and Regional Ecology.

\section{Appendix. Supplementary material}

Supplementary material associated with this article can be found, in the online version, at www.sciencedirect.com, doi:10. 1016/j.envpol.2011.09.027.

\section{References}

Agarwal, T., 2009. Concentration level, pattern and toxic potential of PAHs in traffic soil of Delhi, India. Journal of Hazardous Materials 171, 894-900.

Aichner, B., Glaser, B., Zech, W., 2007. Polycyclic aromatic hydrocarbons and polychlorinated biphenyls in urban soils from Kathmandu, Nepal. Organic Geochemistry 38, 700-715.

Andreoni, V., Cavalca, L., Rao, M.A., Nocerino, G., Bernasconi, S., Dell'Amico, E., Colombo, M., Gianfreda, L., 2004. Bacterial communities and enzyme activities of PAHs polluted soils. Chemosphere 57, 401-412.

BMBS, 2002. Beijing 2000 Population Census Data. Beijing Municipal Bureau of Statistics.

Cai, Q.Y., Mo, C.H., Li, Y.H., Zeng, Q.Y., Katsoyiannis, A., Wu, Q.T., Férard, J.F., 2007. Occurrence and assessment of polycyclic aromatic hydrocarbons in soils from vegetable fields of the Pearl River Delta, South China. Chemosphere 68, 159-168.

Chen, T.B., Zheng, Y.M., Lei, M., Huang, Z.C., Wu, H.T., Chen, H., Fan, K.K., Yu, K., Wu, X., Tian, Q.Z., 2005. Assessment of heavy metal pollution in surface soils of urban parks in Beijing, China. Chemosphere 60, 542-551.

Collins, C.D., Finnegan, E., 2010. Modeling the plant uptake of organic chemicals, including the soil-air-plant pathway. Environmental Science \& Technology.

Cousins, I.T., Beck, A.J., Jones, K.C., 1999. A review of the processes involved in the exchange of semi-volatile organic compounds (SVOC) across the air-soil interface. The Science of the Total Environment 228, 5-24.

Diamond, M.L., Hodge, E., 2007. Urban contaminant dynamics: from source to effect. Environmental Science \& Technology 41, 3796-3800.

Escobedo, F.J., Nowak, D.J., 2009. Spatial heterogeneity and air pollution removal by an urban forest. Landscape and Urban Planning 90, 102-110.

Gao, Y., Zhu, L., 2004. Plant uptake, accumulation and translocation of phenanthrene and pyrene in soils. Chemosphere 55, 1169-1178.

Grahn, P., Stigsdotter, U.K., 2010. The relation between perceived sensory dimensions of urban green space and stress restoration. Landscape and Urban Planning 94, 264-275.

Hafner, W.D., Carlson, D.L., Hites, R.A., 2005. Influence of local human population on atmospheric polycyclic aromatic hydrocarbon concentrations. Environmental Science \& Technology 39, 7374-7379.

Hao, R., Wan, H.F., Song, Y.T., Jiang, H., Peng, S.L., 2007. Polycyclic aromatic hydrocarbons in agricultural soils of the Southern Subtropics, China. Pedosphere 17, 673-680.

Haritash, A.K., Kaushik, C.P., 2009. Biodegradation aspects of polycyclic aromatic hydrocarbons (PAHs): a review. Journal of Hazardous Materials 169, 1-15.

Hassanin, A., Breivik, K., Meijer, S.N., Steinnes, E., Thomas, G.O., Jones, K.C., 2003. PBDEs in European background soils: levels and factors controlling their distribution. Environmental Science \& Technology 38, 738-745.

He, F., Zhang, Z., Wan, Y., Lu, S., Wang, L., Bu, Q., 2009. Polycyclic aromatic hydrocarbons in soils of Beijing and Tianjin region: vertical distribution, correlation with TOC and transport mechanism. Journal of Environmental Sciences 21, 675-685.

Heywood, E., Wright, J., Wienburg, C.L., Black, H.I.J., Long, S.M., Osborn, D. Spurgeon, D.J., 2006. Factors influencing the national distribution of polycyclic aromatic hydrocarbons and polychlorinated biphenyls in British soils. Environmental Science \& Technology 40, 7629-7635.

Jensen, H., Reimann, C., Finne, T.E., Ottesen, R.T., Arnoldussen, A., 2007. PAHconcentrations and compositions in the top $2 \mathrm{~cm}$ of forest soils along a $120 \mathrm{~km}$ long transect through agricultural areas, forests and the city of Oslo, Norway. Environmental Pollution 145, 829-838. 
Jiang, Y.F., Wang, X.T., Wang, F., Jia, Y., Wu, M.H., Sheng, G.Y., Fu, J.M., 2009. Levels, composition profiles and sources of polycyclic aromatic hydrocarbons in urban soil of Shanghai, China. Chemosphere 75, 1112-1118.

Jiao, W.T., Lu, Y.L., Wang, T.Y., Li, J., Han, J.Y., Wang, G., Hu, W.Y., 2009. Polycyclic aromatic hydrocarbons in soils around Guanting Reservoir, Beijing, China. Chemistry and Ecology 25, 39-48.

Jim, C.Y., Chen, W.Y., 2008. Assessing the ecosystem service of air pollutant removal by urban trees in Guangzhou (China). Journal of Environmental Management 88, 665-676.

Kong, F., Yin, H., Nakagoshi, N., Zong, Y., 2010. Urban green space network development for biodiversity conservation: identification based on graph theory and gravity modeling. Landscape and Urban Planning 95, 16-27.

Li, X.H., Ma, L.L., Liu, X.F., Fu, S., Cheng, H.X., Xu, X.B., 2006. Polycyclic aromatic hydrocarbon in urban soil from Beijing, China. Journal of Environmental Sciences 18, 944-950.

Lin, H., Tao, S., Zuo, Q., Coveney, R.M., 2007. Uptake of polycyclic aromatic hydrocarbons by maize plants. Environmental Pollution 148, 614-619.

Liu, S., Tao, S., Liu, W., Dou, H., Liu, Y., Zhao, J., Little, M.G., Tian, Z., Wang, J., Wang, L., Gao, Y., 2008. Seasonal and spatial occurrence and distribution of atmospheric polycyclic aromatic hydrocarbons (PAHs) in rural and urban areas of the North Chinese Plain. Environmental Pollution 156, 651-656.

Lo, A.Y., Jim, C.Y., 2010. Willingness of residents to pay and motives for conservation of urban green spaces in the compact city of Hong Kong. Urban Forestry \& Urban Greening 9, 113-120.

Ma, L.L., Chu, S.G., Wang, X.T., Cheng, H.X., Liu, X.F., Xu, X.B., 2005. Polycyclic aromatic hydrocarbons in the surface soils from outskirts of Beijing, China. Chemosphere 58, 1355-1363.

Macek, T., Mackov, M., Kas, J., 2000. Exploitation of plants for the removal of organics in environmental remediation. Biotechnology Advances 18, 23-34.

Mantis, J., Chaloulakou, A., Samara, C., 2005. PM10-bound polycyclic aromatic hydrocarbons (PAHs) in the Greater Area of Athens, Greece. Chemosphere 59, 593-604.

McLachlan, M.S., Horstmann, M., 1998. Forests as filters of airborne organic pollutants: a model. Environmental Science \& Technology 32, 413-420.

Meijer, S.N., Steinnes, E., Ockenden, W.A., Jones, K.C., 2002. Influence of environmental variables on the spatial distribution of PCBs in Norwegian and U.K. soils: implications for global cycling. Environmental Science \& Technology 36, 2146-2153.

Nam, J.J., Thomas, G.O., Jaward, F.M., Steinnes, E., Gustafsson, O., Jones, K.C., 2008. PAHs in background soils from Western Europe: influence of atmospheric deposition and soil organic matter. Chemosphere 70, 1596-1602.

Nascimento, N.R.d., Nicola, S.M.C., Rezende, M.O.O., Oliveira, T.A., Öberg, G., 2004. Pollution by hexachlorobenzene and pentachlorophenol in the coastal plain of São Paulo state, Brazil. Geoderma 121, 221-232.

Nowak, D.J., Crane, D.E., Stevens, J.C., 2006. Air pollution removal by urban trees and shrubs in the United States. Urban Forestry \& Urban Greening 4, 115-123.

Peng, C., Chen, W., Liao, X., Wang, M., Ouyang, Z., Jiao, W., Bai, Y., 2011. Polycyclic aromatic hydrocarbons in urban soils of Beijing: status, sources, distribution and potential risk. Environmental Pollution 159, 802-808.

Rafiee, R., Salman Mahiny, A., Khorasani, N., 2009. Assessment of changes in urban green spaces of Mashad city using satellite data. International Journal of Applied Earth Observation and Geoinformation 11, 431-438.

Ravindra, K., Sokhi, R., Van Grieken, R., 2008. Atmospheric polycyclic aromatic hydrocarbons: source attribution, emission factors and regulation. Atmospheric Environment 42, 2895-2921.
Schipperijn, J., Stigsdotter, U.K., Randrup, T.B., Troelsen, J., 2010. Influences on the use of urban green space - a case study in Odense, Denmark. Urban Forestry \& Urban Greening 9, 25-32.

Shan, Y., Jingping, C., Liping, C., Zhemin, S., Xiaodong, Z., Dan, W., Wenhua, W., 2007. Effects of vegetation status in urban green spaces on particle removal in a street canyon atmosphere. Acta Ecologica Sinica 27, 4590-4595.

Staci, L., Simonich, R.A.H., 1994. Importance of vegetation in removing polycyclic aromatic hydrocarbons from the atmosphere. Nature 370.

Szabová, E., Zeljenková, D., Nescáková, E., Simko, M., Turecký, L., 2008. Polycyclic aromatic hydrocarbons and occupational risk factor. Reproductive Toxicology 26, 74.

Tam, N.F.Y., Wong, Y.S., 2008. Effectiveness of bacterial inoculum and mangrove plants on remediation of sediment contaminated with polycyclic aromatic hydrocarbons. Marine Pollution Bulletin 57, 716-726.

Tang, L., Tang, X.Y., Zhu, Y.G., Zheng, M.H., Miao, Q.L., 2005. Contamination of polycyclic aromatic hydrocarbons (PAHs) in urban soils in Beijing, China. Environment International 31, 822-828.

Wang, R., Cao, H., Li, W., Wang, W., Wang, W., Zhang, L., Liu, J., Ouyang, H., Tao, S. 2011a. Spatial and seasonal variations of polycyclic aromatic hydrocarbons in Haihe Plain, China. Environmental Pollution 159, 1413-1418.

Wang, W., Massey Simonich, S.L., Giri, B., Xue, M., Zhao, J., Chen, S., Shen, H. Shen, G., Wang, R., Cao, J., Tao, S., 2011b. Spatial distribution and seasonal variation of atmospheric bulk deposition of polycyclic aromatic hydrocarbons in Beijing-Tianjin region, North China. Environmental Pollution 159, 287-293.

Wang, Z., Chen, J., Qiao, X., Yang, P., Tian, F., Huang, L., 2007. Distribution and sources of polycyclic aromatic hydrocarbons from urban to rural soils: a case study in Dalian, China. Chemosphere 68, 965-971.

Wania, F., McLachlan, M.S., 2001. Estimating the influence of forests on the overal fate of semivolatile organic compounds using a multimedia fate model. Environmental Science \& Technology 35, 582-590.

Watts, A.W., Ballestero, T.P., Gardner, K.H., 2006. Uptake of polycyclic aromatic hydrocarbons (PAHs) in salt marsh plants Spartina alterniflora grown in contaminated sediments. Chemosphere 62, 1253-1260.

Wong, F., Harner, T., Liu, Q.T., Diamond, M.L., 2004. Using experimental and forest soils to investigate the uptake of polycyclic aromatic hydrocarbons (PAHs) along an urban-rural gradient. Environmental Pollution 129, 387-398.

Xia, X., Chen, X., Liu, R., Liu, H., 2011. Heavy metals in urban soils with various types of land use in Beijing, China. Journal of Hazardous Materials 186, 2043-2050.

$\mathrm{Xu}, \mathrm{S}$., Liu, W., Tao, S., 2005. Emission of polycyclic aromatic hydrocarbons in China. Environmental Science \& Technology 40, 702-708.

Yang, J., McBride, J., Zhou, J., Sun, Z., 2005. The urban forest in Beijing and its role in air pollution reduction. Urban Forestry \& Urban Greening 3, 65-78.

Yu, X.Z., Gao, Y., Wu, S.C., Zhang, H.B., Cheung, K.C., Wong, M.H., 2006. Distribution of polycyclic aromatic hydrocarbons in soils at Guiyu area of China, affected by recycling of electronic waste using primitive technologies. Chemosphere 65, 1500-1509.

Yu, Y., Guo, H., Liu, Y., Huang, K., Wang, Z., Zhan, X., 2008. Mixed uncertainty analysis of polycyclic aromatic hydrocarbon inhalation and risk assessment in ambient air of Beijing. Journal of Environmental Sciences 20, 505-512.

Zhang, X.X., Cheng, S.P., Zhu, C.J., Sun, S.L., 2006a. Microbial PAH-degradation in soil: degradation pathways and contributing factors. Pedosphere 16, 555-565.

Zhang, Y., Tao, S., Cao, J., Coveney, R.M., 2006b. Emission of polycyclic aromatic hydrocarbons in China by County. Environmental Science \& Technology 41 683-687. 